\title{
Bridging the Gap between Evidence and Real-World Practice for Liver Cancer Screening in South Korea
}

Chang-Mo Oh

Department of Preventive Medicine, Kyung Hee University School of Medicine, Seoul, Korea

See "The Impact of National Surveillance for Liver Cancer: Results from Real-World Setting in Korea" by Jin Won Kwon, et al. on page 108 , Vol. 14. No. 1, 2020

Although incidence and mortality rates for liver cancer have decreased continuously since 1999 in South Korea, ${ }^{1}$ the burden of liver cancer is still high. In 2018, more than 10,000 people died of liver cancer, and death from liver cancer accounts for about 13\% of all cancer deaths in South Korea. South Korea has the highest mortality rate of liver cancer among the Organisation for Economic Co-operation and Development (OECD) countries, and it is about two times higher than liver cancer mortality rates in Japan, which ranks 2nd among the OECD countries. One of the main reasons for the high disease burden of liver cancer is the high prevalence of hepatitis B virus infection in South Korea. ${ }^{2}$

In 2003, the Korean government introduced the national liver cancer screening program for groups at high risk of contracting hepatitis $\mathrm{B}$, hepatitis $\mathrm{C}$, or other liver diseases using liver ultrasonography and serum alpha-fetoprotein measurement to reduce the high disease burden of liver cancer. However, liver cancer is very rare in Western countries. Hence, few countries except for Japan, China, and South Korea have introduced a nationwide liver cancer screening program. Moreover, there was a lack of evidence that liver cancer screening using liver ultrasonography and serum alpha-fetoprotein measurement could reduce mortality rates from liver cancer. Only one randomized controlled trial in China has reported that liver cancer screening with combined liver ultrasonography and serum alpha-fetoprotein measurement can reduce the mortality risk from liver cancer. ${ }^{3}$ However, this study was criticized by the American Association for the Study of Liver Disease for improper study design and statistical invalidation. ${ }^{4}$ A mass screening program should not be implemented unless it can be shown that the benefit outweighs the risk of harm. ${ }^{5}$ Until now, the rationale for implementing a national liver cancer screening program was not clear. ${ }^{4,6}$ However, some clinicians who support national liver cancer screening expected that liver ultrasonography and serum alpha-fetoprotein measurement would help detect liver cancer in asymptomatic patients earlier, and therefore, the earlier treatment for liver cancer would increase the overall survival rate of patients with liver cancer. ${ }^{7,8}$

Although a randomized controlled trial is considered the golden standard to evaluate the effectiveness of a screening program, it is very difficult to perform a randomized controlled trial in a real-world setting. ${ }^{4}$ Therefore, in reality, well-designed observational studies would be necessary to assess the effectiveness of liver cancer screening at reducing mortality using liver ultrasonography and serum alpha-fetoprotein measurement. However, observational studies aimed at evaluating the effectiveness of the cancer screening program were destined to be biased owing to self-selection bias, lead time bias, and length bias. ${ }^{9}$ After adjusting for lead time, and assigning all-cause mortality as the primary outcome, the cohort study may have had a high level of evidence among the observational studies. In addition, this study has another advantage of using the National Health Insurance Service database which can be representative for all liver cancer patients in South Korea.

Considering this, a study by Kwon et al. ${ }^{10}$ showed great importance for national liver cancer screening in South Korea. Kwon et al. ${ }^{10}$ showed that liver cancer screening using liver ultrasonography and serum alpha-fetoprotein measurement reduced all-cause mortality risk among participants after adjustment for lead time and possible covariates in the real-world

\footnotetext{
Correspondence to: Chang-Mo Oh

Department of Preventive Medicine, Kyung Hee University School of Medicine, 26 Kyungheedae-ro, Dongdaemun-gu, Seoul 02447, Korea

Tel: +82-2-961-2265, Fax: +82-2-969-0792,E-mail: kachas@naver.com

pISSN 1976-2283 eISSN 2005-1212 https://doi.org/10.5009/gnl19388

(a) This is an Open Access article distributed under the terms of the Creative Commons Attribution Non-Commercial License (http://creativecommons.org/licenses/by-nc/4.0) which permits unrestricted non-commercial use, distribution, and reproduction in any medium, provided the original work is properly cited.
} 
setting. This new finding will provide a basis for clinicians to strongly recommend patients with liver diseases such as hepatitis B, hepatitis C, or liver cirrhosis to participate in a national liver cancer screening program. Until now, only two out of five high-risk patients with hepatitis B, hepatitis C, or liver diseases had participated in the national liver cancer screening program. The nationwide efforts will be necessary to increase participation rates and improve the quality of the liver cancer screening program in South Korea.

\section{CONFLICTS OF INTEREST}

No potential conflict of interest relevant to this article was reported.

\section{ORCID}

Chang-Mo Oh

https://orcid.org/0000-0002-5709-9350

\section{REFERENCES}

1. Jung KW, Won YJ, Kong HJ, Lee ES. Cancer statistics in Korea: incidence, mortality, survival, and prevalence in 2016. Cancer Res Treat 2019;51:417-430.

2. Kim H, Shin AR, Chung HH, et al. Recent trends in hepatitis B virus infection in the general Korean population. Korean J Intern Med 2013;28:413-419.

3. Zhang BH, Yang BH, Tang ZY. Randomized controlled trial of screening for hepatocellular carcinoma. J Cancer Res Clin Oncol 2004;130:417-422.

4. Sherman M, Bruix J, Porayko M, Tran T; AASLD Practice Guidelines Committee. Screening for hepatocellular carcinoma: the rationale for the American Association for the Study of Liver Diseases recommendations. Hepatology 2012;56:793-796.

5. Silvestri GA. Screening for lung cancer: it works, but does it really work? Ann Intern Med 2011;155:537-539.

6. Kansagara D, Papak J, Pasha AS, et al. Screening for hepatocellular carcinoma in chronic liver disease: a systematic review. Ann Intern Med 2014;161:261-269.

7. Singal AG, Pillai A, Tiro J. Early detection, curative treatment, and survival rates for hepatocellular carcinoma surveillance in patients with cirrhosis: a meta-analysis. PLoS Med 2014;11:e1001624.

8. Zhao C, Nguyen MH. Hepatocellular carcinoma screening and surveillance: practice guidelines and real-life practice. J Clin Gastroenterol 2016;50:120-133.

9. Kramer BS, Croswell JM. Cancer screening: the clash of science and intuition. Annu Rev Med 2009;60:125-137.

10. Kwon JW, Tchoe HJ, Lee J, Suh JK, Lee JH, Shin S. The impact of national surveillance for liver cancer: results from real-world setting in Korea. Gut Liver 2020;14:108-116. 